\title{
Clareza, concisão e coesão: princípios e métricas de legibilidade aplicados ao texto de pós-graduandos em Ciência da Informação*
}

\section{Clarity, conciseness, and cohesion: readability principles and metrics applied to information science graduate students' text}

Vinícius Medina Kern ${ }^{1}$, Eliane Pellegrini ${ }^{2}$, Thais Carrier Mendonça ${ }^{3}$, Priscila Basto Fagundes ${ }^{4}$, Leonardo Lima Günther ${ }^{5}$, Josiane Mello ${ }^{6}$, Márcio José Sembay ${ }^{7}$, Bianca Ferreira Hernandez $z^{8}$, Rebeca Silva Fernandes de Moura Andrade $^{9}$, Amabile Costa ${ }^{10}$, Carolina Martins Cechinel $^{11}$, Mariane Sperber ${ }^{12}$, Rosane Oribka ${ }^{13}$, Gislaine Parra Freund $^{14}$, Edson Mário Gavron ${ }^{15}$, José María Vitalitii ${ }^{16}$, Luiz Felipe Correa Chiaradia ${ }^{17}$, Graciela Sardo Menezes ${ }^{18}$, Everton Rodrigues Barbosa ${ }^{19}$, Marcela Gaspar Custódio ${ }^{20}$, Dirnele Carneiro Garcez ${ }^{21}$, Marcela Reinhardt de Souza $^{22}$, Letícia Silvana dos Santos Estácio ${ }^{23}$, Eliane Rodrigues Mota Orelo ${ }^{24}$, Andreia dos Santos ${ }^{25}$, Raffaela Dayane Afonso ${ }^{26}$

${ }^{1}$ Universidade Federal de Santa Catarina (UFSC), Florianópolis, SC, Brasil. ORCID: http://orcid.org/0000-0001-9240-304X

2 Universidade Federal de Santa Catarina (UFSC), Florianópolis, SC, Brasil. ORCID: https://orcid.org/0000-0001-5900-9753

${ }^{3}$ Ministério Público do Estado de Santa Catarina, Florianópolis, SC, Brasil. ORCID: https://orcid.org/0000-0002-6186-3155

${ }^{4}$ Universidade Federal de Santa Catarina (UFSC), Florianópolis, SC, Brasil. ORCID: https://orcid.org/0000-0002-9461-311X

${ }^{5}$ Universidade Federal de Santa Catarina (UFSC), Florianópolis, SC, Brasil. ORCID: https://orcid.org/0000-0001-6179-5247

${ }^{6}$ Universidade Federal de Santa Catarina (UFSC), Florianópolis, SC, Brasil. ORCID: https://orcid.org/0000-0003-4697-3978

7 Universidade Federal de Santa Catarina (UFSC), Florianópolis, SC, Brasil. ORCID: https://orcid.org/0000-0002-7648-8861

8 Universidade Federal de Santa Catarina (UFSC), Florianópolis, SC, Brasil. ORCID: https://orcid.org/0000-0002-3742-8882

${ }^{9}$ Universidade Federal de Santa Catarina (UFSC), Florianópolis, SC, Brasil. ORCID: https://orcid.org/0000-0002-3150-9032

10 Universidade Federal de Santa Catarina (UFSC), Florianópolis, SC, Brasil. ORCID: https://orcid.org/0000-0001-9505-0614

11 Universidade Federal de Santa Catarina (UFSC), Florianópolis, SC, Brasil. ORCID: https://orcid.org/0000-0003-1835-7481

12 Universidade Federal de Santa Catarina (UFSC), Florianópolis, SC, Brasil. ORCID: https://orcid.org/0000-0002-0282-8237

13 Universidade Federal de Santa Catarina (UFSC), Florianópolis, SC, Brasil. ORCID: https://orcid.org/0000-0003-0134-7615

14 Universidade Federal de Santa Catarina (UFSC), Florianópolis, SC, Brasil. ORCID: https://orcid.org/0000-0002-2402-124X

15 Universidade Federal de Santa Catarina (UFSC), Florianópolis, SC, Brasil. ORCID: https://orcid.org/0000-0002-8761-2178

16 Universidad del Aconcagua, Universidad Nacional de Quilmes, Florianópolis, SC, Brasil. ORCID: https://orcid.org/0000-0003-3404-9753

17 Universidade Federal de Santa Catarina (UFSC), Florianópolis, SC, Brasil. ORCID: https://orcid.org/0000-0002-9744-6986

18 Universidade Federal de Santa Catarina (UFSC), Florianópolis, SC, Brasil. ORCID: https://orcid.org/0000-0002-3095-5727

19 Universidade Federal de Santa Catarina (UFSC), Florianópolis, SC, Brasil. ORCID: https://orcid.org/0000-0002-1111-5861

20 Universidade Federal de Santa Catarina (UFSC), Florianópolis, SC, Brasil. ORCID: https://orcid.org/0000-0003-1795-6618

${ }^{21}$ Universidade Federal de Santa Catarina (UFSC), Florianópolis, SC, Brasil. ORCID: https://orcid.org/0000-0001-6694-2138

22 Universidade do Estado de Santa Catarina (UDESC), Florianópolis, SC, Brasil. ORCID: https://orcid.org/0000-0003-4870-5563

${ }^{23}$ Universidade Federal de Santa Catarina (UFSC), Florianópolis, SC, Brasil. ORCID: https://orcid.org/0000-0002-1447-6590

${ }^{24}$ Universidade Federal de Santa Catarina (UFSC), Florianópolis, SC, Brasil. ORCID: https://orcid.org/0000-0003-2225-0302

${ }^{25}$ Universidade Federal de Santa Catarina (UFSC), Florianópolis, SC, Brasil. ORCID: https://orcid.org/0000-0003-1696-478X

${ }^{26}$ Universidade Federal de Santa Catarina (UFSC), Florianópolis, SC, Brasil. ORCID: https://orcid.org/0000-0002-2254-1639

Autor para correspondência/Mail to:Vinícius Medina Kern, v.m.kern@ufsc.br

Recebido/Submitted: 20 de novembro de 2020; Aceito/Approved: 03 de fevereiro de 2021

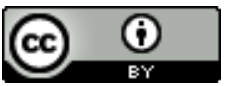

Copyright (c) 2021 Kern et al.. Todo o conteúdo da Revista (incluindo-se instruções, política editorial e modelos) está sob uma licença Creative Commons Atribuição 4.0 Internacional. Ao serem publicados por esta Revista, os artigos são de livre uso em ambientes educacionais, de pesquisa e não comerciais, com atribuição de autoria obrigatória. Mais informações em http://revistas.ufpr.br/atoz/about/submissions\#copyrightNotice.

*Publicado anteriormente como preprint por Kern et al. (2019). Disponível em https://osf.io/5vqce/ 


\begin{abstract}
Resumo
Introdução: a barreira da língua dificulta publicar em inglês mesmo quando há mérito científico, pois o problema começa em português, na dificuldade em escrever como a ciência requer. Qual o impacto da aplicação de princípios de clareza, concisão e coesão na extensão e legibilidade de textos científicos? Esta pesquisa objetivou verificar esse impacto ao comparar extensão e indicadores de legibilidade antes e após a aplicação dos princípios. Método: vinte e cinco estudantes de pós-graduação em Ciência da Informação anotaram um texto científico próprio e o de três colegas, em revisão por pares duplo-cega, indicando problemas de estilo de quatro tipos: palavra desnecessária, distância sujeito-verbo excessiva, nominalização excessiva e contextualização tardia. Cada autor reelaborou seu próprio texto para resolver os problemas anotados. Os textos originais e reelaborados foram comparados em extensão e escore de facilidade de leitura de Flesch. Textos originais e reelaborados da literatura também foram mensurados como referência. Resultados: Todos os textos diminuíram em extensão após reelaborados, embora tenha havido mais atenção a problemas gramaticais do que aos quatro problemas de estilo. Houve 13 aumentos, duas manutenções e 10 diminuições nos escores de legibilidade. Esse resultado é compatível com o estudo-referência com textos da literatura. Conclusão: a aplicação dos princípios de legibilidade diminui a extensão e, em acordo com a literatura, tem impacto duvidoso no escore de legibilidade. Resta investigar a traduzibilidade comparada para verificar o pressuposto de que aplicar os princípios é "escrever em inglês em português".
\end{abstract}

Palavras-chave: Pós-graduação em ciência da informação; Métricas de legibilidade; Comunicação científica; Revisão pelos pares; Redação científica.

\begin{abstract}
Introduction: The language barrier makes it difficult to publish in English, even when there is scientific merit, as the problem starts in Portuguese, in the difficulty of following scientific writing principles. What is the impact of applying principles of clarity, conciseness, and cohesion in the extension and readability of scientific texts? This research aimed to verify this impact when comparing extension and readability indicators before and after applying those principles. Method: Twenty-five Information Science graduate students annotated their own scientific text and that of three colleagues, in a double-blind review, indicating writing style problems of four types: unnecessary word, excessive subject-verb distance, excessive nominalization, and late contextualization. Each author then reworked their own text to solve the problems. The original and reworked texts were compared in length and Flesch Reading Ease score. Original and reworked texts from the literature were also compared, as a reference. Results: All texts were shortened after rework although annotations were directed most to grammatical problems than to the four style problems. There were 13 increases, 2 maintenance, and 10 decreases in the readability scores. This result is compatible with the benchmark study with texts from the literature. Conclusions: Applying readability principles improves conciseness but, in accordance with the literature, has a dubious impact on the readability score. Compared translatability remains an open research topic, to verify the assumption that applying the principles equates to "write in English in Portuguese".
\end{abstract}

Keywords: Graduate studies in information science; Readability metrics; Scholarly communication; Peer review; Scholarly writing.

\title{
INTRODUÇÃO
}

O Brasil tem aumentado sua participação relativa na publicação científica internacional. De 64 artigos em 1970 na base do Institute for Scientific Information ${ }^{1}$ : Science Indicators / CD-Rom 2001 e Web of Science (0,019\% do total), chegou a 1.887 artigos (0,44\%) em 1981 e a 10.555 (1,4\%) em 2001 (Guimarães, 2004). Posteriormente, atingiu 2,7\% em 2008 e 2,9\% em 2014 (UNESCO, 2011).

Neste artigo, tratamos do estilo de redação na língua franca da ciência internacional, o inglês, usualmente restrito a guias clássicos e gerais muito reeditados, como Strunk e White (1999) e Zinsser (2001), com versões originais em $1920^{2}$ e $1976^{3}$, respectivamente. Aqui, adotamos a abordagem prática de Sheffield (2011), que propõe exemplos e exercícios.

Redigir texto claro, como é comum em inglês e como requer a ciência (Rabinowitz \& Vogel, 2009), é um desafio para brasileiros, alfabetizados sob uma tradição pródiga em contorções sintáticas. O Hino Nacional Brasileiro é referência plausível desse estilo. O Quadro 1 mostra que os primeiros versos do Hino, colocados em ordem sintática direta (sujeito-verbo-objeto), são passíveis de tradução automática, mantendo o significado. Em vez disso, na tradução automática do texto original, perde-se ou altera-se o sujeito da sentença - de "As margens plácidas" para "They" (Eles). Nesse sentido, a mera transposição de texto sintaticamente convoluto para a ordem direta é uma aproximação a "escrever em inglês em português".

Para Volpato (2011), o problema não é o inglês, mas o pensamento. Não adianta traduzir para inglês um texto que não atende aos critérios da ciência. Ele enfatiza o mérito científico, mas também discute o estilo, no sexto capítulo de seu livro "Bases teóricas para redação científica" (Volpato, 2007). Os critérios de estilo para o texto científico em inglês favorecem a legibilidade e assemelham-se aos critérios para textos em inglês em geral. Dessa forma, parece plausível que textos que seguem esses critérios alcancem melhores índices de legibilidade, bem como sejam mais satisfatoriamente traduzíveis entre o português e o inglês.

A boa legibilidade está associada a mais downloads, citações e prêmios (Fages, 2020). Há métricas para estimar a legibilidade, como os índices de Flesch e de Kincaid (Kincaid, Fishburne Jr., Rogers, \& Chissom, 1975). Há

\footnotetext{
${ }^{1}$ Hoje parte da empresa Clarivate.

${ }^{2}$ Strunk Jr., W. (1920). The elements of style. New York, Harcourt: Brace and Howe. Disponível em: https://catalog.loc.gov/vwebv/holdingsInfo?searchId=4810\&recCount =25\&recPointer=0\&bibId=9657813. Acesso em: 28 jan. 2021.

${ }^{3}$ Zinsser, W. (1976). On writing well: an informal guide to writing nonfiction. 1st ed. New York: Harper \& Row. Disponível em: https://catalog.loc.gov/vwebv/holdingsInfo?searchId=4850\&recCount=25\&recPointer $=12 \&$ bibId=1270946. Acesso em: 28 jan. 2021.
} 


\begin{tabular}{|c|c|}
\hline Sintaxe original & Sintaxe em ordem direta \\
\hline $\begin{array}{l}\text { Ouviram do Ipiranga as margens plácidas de um povo } \\
\text { heroico o brado retumbante, e o sol da liberdade, em } \\
\text { raios fúlgidos, brilhou no céu da pátria nesse instante. }\end{array}$ & $\begin{array}{l}\text { As margens plácidas do Ipiranga ouviram o brado re- } \\
\text { tumbante de um povo heroico, e o sol da liberdade } \\
\text { brilhou, em raios fúlgidos, no céu da pátria neste ins- } \\
\text { tante. }\end{array}$ \\
\hline $\begin{array}{l}\text { Tradução automática: } \\
\text { They heard from the Ipiranga the placid banks of a heroic } \\
\text { people the resounding shout, and the sun of freedom, in } \\
\text { brilliant rays, shone in the heaven of the country at that } \\
\text { moment. }\end{array}$ & $\begin{array}{l}\text { Tradução automática: } \\
\text { The placid banks of the Ipiranga heard the resounding } \\
\text { cry of a heroic people, and the sun of freedom shone, in } \\
\text { brilliant rays, in the heaven of the country at this moment. }\end{array}$ \\
\hline $\begin{array}{l}\text { Tradução automática reversa: } \\
\text { Eles ouviram do Ipiranga as margens plácidas de um } \\
\text { povo heroico o grito ressonante, e o sol da liberdade, } \\
\text { em raios brilhantes, brilhou no céu do país naquele } \\
\text { momento. }\end{array}$ & $\begin{array}{l}\text { Tradução automática reversa: } \\
\text { As plácidas margens do Ipiranga ouviram o grito re- } \\
\text { tumbante de um povo heroico, e o sol da liberdade } \\
\text { brilhou, em raios brilhantes, no céu do país neste mo- } \\
\text { mento. }\end{array}$ \\
\hline
\end{tabular}

Quadro 1. Tradução automática dos primeiros versos do Hino Nacional Brasileiro.

Fonte: Elaborado pelos autores, via Google $\operatorname{Tradutor}^{a}$ (31 maio 2018).

${ }^{a}$ https://translate.google.com

ferramentas de cálculo disponíveis online e em editores de texto como o MS-Word, embora a função inexista em algumas instalações e necessite configuração específica na versão em português do software, pois está desabilitada por default, contribuindo para manter o tema virtualmente desconhecido dos brasileiros.

A disciplina Redação e Avaliação Científica foi criada no Programa de Pós-Graduação em Ciência da Informação da Universidade Federal de Santa Catarina com foco na redação científica segundo princípios de clareza, concisão e coesão, principalmente no nível do parágrafo. No escopo da disciplina, esta pesquisa buscou responder a pergunta: qual o impacto na extensão e legibilidade de textos de pós-graduandos em Ciência da Informação ao adotar princípios de concisão, coesão e clareza? As próximas seções apresentam uma breve discussão sobre estilo científico e métricas de legibilidade, os procedimentos metodológicos, os resultados e sua discussão, bem como considerações finais.

\section{ESTILO CIENTÍFICO E MÉTRICAS DE LEGIBILIDADE}

O estilo de redação é a maneira de expressar-se por escrito. (Meadows, 1999, p. 121) discute a legibilidade de textos científicos e afirma que "[o] que o leitor absorve de um livro ou artigo depende em parte da maneira como ele está escrito e em parte do conhecimento prévio que o leitor possui". Os autores deste artigo, em maioria brasileiros, foram instruídos sobre questões de gramática em sua educação básica, mas não recordam de experiências de aprendizagem significativas sobre estilo de texto. Com efeito, o tema parece merecer pouca atenção no Brasil, mesmo no meio científico.

Volpato (2007) é uma exceção. Aborda o estilo científico e lista entre seus princípios: construções lógicas e objetivas, palavras simples, frases curtas e sintéticas, clareza, eliminação de redundâncias, digressões e adjetivos desnecessários, tempo verbal consistente (procedimentos e resultados no passado, conclusão no presente), encadeamento de ideias do geral para o específico, precisão terminológica, voz ativa (de preferência à passiva), construções afirmativas, uso de conjunções e lógica da construção de frases e parágrafos.

Em inglês, Strunk e White (1999) é um guia clássico geral que prescreve principalmente a concisão e o uso da voz ativa. Zinsser (2001) trata de muitos aspectos e tipos de redação de não-fiç̧ão. Quanto ao estilo, condena o texto confuso e prescreve a concisão, ilustrando seu argumento com a edição de seu próprio texto, com muitas eliminações e simplificações.

Essa literatura prescritiva dá exemplos, mas raramente exercícios em quantidade e qualidade. Nesse sentido, Sheffield (2011) favorece o aprendiz interessado ao discutir quatro critérios de clareza, concisão e coesão com exemplos e exercícios. Clareza é a propriedade do texto inteligível, concisão é a exposição em poucas palavras e coesão, conforme Sheehan (2013), trata de integrar e conectar ideias ao longo de orações, sentenças e parágrafos. Sheffield (2011) propõe melhorar a clareza, concisão e coesão com estas técnicas:
a) omitir palavras desnecessárias;
b) expressar ações em verbos (evitar nominalizações);
c) colocar verbos próximos aos sujeitos; e
d) dar informação familiar primeiro (isto é, a contextualização necessária para entender). 


\begin{tabular}{|l|l|l|}
\hline Escore & Nível de formação & Comentários \\
\hline $100,0-90,0$ & $5^{\circ}$ ano fundamental & $\begin{array}{l}\text { Muito fácil de ler. Facilmente compreendido por um estudante } \\
\text { médio de } 11 \text { anos de idade. }\end{array}$ \\
\hline $90,0-80,0$ & $6^{\circ}$ ano & Fácil de ler. Inglês de conversação para os consumidores. \\
\hline $80,0-70,0$ & $7^{\circ}$ ano & Relativamente fácil de ler. \\
\hline $70,0-60,0$ & $8^{\circ}$ e $9^{\circ}$ anos & $\begin{array}{l}\text { Inglês simples. Facilmente compreendido por estudantes de } 13 \text { a } \\
15 \text { anos de idade. }\end{array}$ \\
\hline $60,0-50,0$ & Ensino médio & Relativamente difícil de ler. \\
\hline $50,0-30,0$ & Universitário & Difícil de ler. \\
\hline $30,0-0,0$ & Graduado & Muito difícil de ler. Melhor entendido por universitários graduados. \\
\hline
\end{tabular}

Tabela 1. Interpretação dos escores de Flesch Reading Ease (FRE).

Fonte: Wikipedia contributors (2021, tradução nossa).

Palavras desnecessárias distraem o leitor, que espera ações em verbos (e não em substantivos - nominalizações). A distância entre o sujeito e o verbo dificulta ao leitor entender quem faz o quê. A informação tardia rompe o fluxo de leitura, mantendo o leitor em suspense. Todos esses problemas ocorrem localmente, no parágrafo, mas a informação ou contextualização tardia, que danifica a coesão, também ocorre ao longo do texto. Uma sentença coesiva liga-se às precedentes ao iniciar com informação contextual, já introduzida antes, e terminando com novas informações.

A escolha de palavras simples (por exemplo, "usual" em vez de "consuetudinário") e a solução de problemas de estilo, tornando o texto claro, conciso e coeso, usualmente reduzem sua extensão. Essa mudança é captada por estatísticas de legibilidade como o teste Flesch Reading Ease, ou FRE (teste de facilidade de leitura de Flesch), dado pela Fórmula 1 (Flesch, 1948; Kincaid et al., 1975) e interpretado conforme a Tabela 1. As constantes na fórmula foram arbitradas empiricamente para que os escores caiam no intervalo de 0 a 100.

$$
206,835-1,015 \times\left(\frac{\text { total de palavras }}{\text { total de sentenças }}\right)-84,6 \times\left(\frac{\text { total de sılabas }}{\text { total de palavras }}\right)
$$

O FRE independe da extensão do texto, já que mede a relação entre as quantidades de sílabas, palavras e sentenças. Foi construído para a língua inglesa, mas pode ser usado para o português, embora os escores não sejam equivalentes, dadas as diferenças de sílabas e tamanhos de palavras, bem como as distintas construções sintáticas em cada língua.

Como limitação, observe-se que o FRE é um indicador de qualidade de texto (Fages, 2020), mas um FRE maior não garante um texto melhor, nem substitui a análise perita do texto. Também não exploramos outros indicadores de legibilidade como os de Gunning, de Fry, de McLaughlin, entre outros (Wikipedia contributors, 2018). O escore não é necessariamente afetado pela inversão sintática, que pode ocorrer sem mudar o número de sílabas, palavras e sentenças - por exemplo, os mesmos 17,9 pontos ("muito difícil de ler") se aplicam tanto a "Ouviram do Ipiranga as margens plácidas de um povo heroico o brado retumbante" quanto a "As margens plácidas do Ipiranga ouviram o brado retumbante de um povo heroico".

Como regra, menos palavras por sentença e menos sílabas por palavra melhoram o escore de legibilidade FRE. Por isso, usar palavras simples e cortar palavras desnecessárias tende a aumentar o indicador de legibilidade, mas o efeito é menos óbvio para as outras três intervenções propostas por Sheffield (2011), de forma que a melhora do indicador de legibilidade ao aplicar princípios de estilo é apenas uma expectativa, uma heurística que adotamos neste estudo. Partimos dessa expectativa de que textos claros, concisos e coesos são legíveis e que isso deve resultar em melhores métricas de legibilidade. A próxima seção descreve os procedimentos de pesquisa para verificar o efeito da aplicação de princípios de estilo na extensão e nos indicadores de legibilidade de textos de pós-graduandos.

\section{PROCEDIMENTOS METODOLÓGICOS}

A pesquisa foi conduzida no escopo da disciplina de dois créditos Redação e Avaliação Científica, criada no Programa de Pós-Graduação em Ciência da Informação da Universidade Federal de Santa Catarina em 2018, com foco na redação científica segundo critérios de estilo bem estabelecidos na ciência internacional, principalmente no nível do parágrafo. É uma pesquisa quantitativa, pois apresenta estatísticas de legibilidade, mas também traz uma apreciação informal do professor da disciplina.

Vinte e cinco estudantes, dos quais 13 de mestrado e 12 de doutorado, selecionaram, em março de 2018, uma seção introdutória de projeto ou artigo científico próprio, com extensão aproximada entre uma e duas páginas e aprovada pelo professor para a atividade. Seguiram-se etapas de preparação para a análise, análise do próprio texto e análise anônima de três textos de colegas. Todos os 25 estudantes participantes entregaram um 


\begin{tabular}{|c|c|}
\hline Texto original & Texto em português \\
\hline $\begin{array}{l}\text { This component will chiefly involve a description and } \\
\text { quantitative analysis of the study's data collection pro- } \\
\text { cess. }\end{array}$ & $\begin{array}{l}\text { Este componente envolverá principalmente uma des- } \\
\text { crição e análise quantitativa do processo de coleta de } \\
\text { dados do estudo. }\end{array}$ \\
\hline $\begin{array}{l}\text { Problemas (palavras desnecessárias } \mathrm{e} \\
\text { nominalizações): }\end{array}$ & $\begin{array}{l}\text { Problemas (palavras desnecessárias } \mathrm{e} \\
\text { nominalizações ): }\end{array}$ \\
\hline $\begin{array}{l}\text { This component will chiefly involve a description and } \\
\text { quantitative analysis of the study's data collection } \\
\text { process. }\end{array}$ & $\begin{array}{l}\text { Este componente envolverá principalmente uma } \\
\text { descrição e análise quantitativa do processo de } \\
\text { coleta de dados do estudo. }\end{array}$ \\
\hline $\begin{array}{l}\text { Versão reescrita: } \\
\text { This component describes and quantitatively analyzes the } \\
\text { data collection process. }\end{array}$ & $\begin{array}{l}\text { Versão reescrita: } \\
\text { Este componente descreve e analisa quantitativa- } \\
\text { mente o processo de coleta de dados. }\end{array}$ \\
\hline
\end{tabular}

Quadro 2. Uma solução para a revisão de um texto com dois tipos de problemas de estilo Texto original Texto em português. Fonte: Excertos de Sheffield (2011, tradução nossa).

parecer sobre o próprio texto e três pareceres sobre textos de colegas. Um vigésimo sexto estudante desistiu da disciplina no momento de entregar as análises e, dessa forma, os três pareceres para seu texto foram desperdiçados e três estudantes receberam um a menos, totalizando 97 pareceres - 25 ao próprio texto e 72 pareceres anônimos dos pares. O processo foi concluído com entrevistas professor-estudante sobre a qualidade da experiência e reelaboração do próprio texto. O professor elaborou estatísticas de extensão e legibilidade.

A pesquisa partiu da expectativa de que o uso de princípios de clareza, concisão e coesão tende a diminuir a extensão e a aumentar o escore de legibilidade dos textos. Nesse sentido, o professor selecionou trechos originais e reelaborados de Sheffield (2011) para servir como referência ou termo de comparação para a mensuração da legibilidade encontrada nos textos dos alunos, já que são textos submetidos aos mesmos princípios de estilo.

A preparação dos estudantes incluiu a resolução dos oito exercícios propostos por Sheffield (2011) sobre sentenças e parágrafos com problemas de estilo, usando as quatro técnicas já mencionadas: omitir palavras desnecessárias, expressar ações em verbos (evitar nominalizações em excesso), colocar verbos próximos a seus sujeitos e dar informação familiar primeiro (e não tardiamente). Os exercícios foram vertidos para o português, como no exemplo sucinto do Quadro 2.

Seguiu-se a análise do próprio texto por cada estudante, aplicando as mesmas quatro técnicas de revisão para marcar os problemas de estilo no texto. Essa análise não foi compartilhada com a turma nesse momento, para evitar enviesar as análises posteriores pelos colegas. A Figura 1 exemplifica a marcação de texto a omitir (caracteres tachados) e distância sujeito-verbo excessiva (fundo vermelho).

23 O surgimento de legislações, que visam garantir o acesso às informações desde sua 24 geração até a distribuição irrestrita dos dados, ganhą espaço nas democracias modernas e introduz uma

Figura 1. Marcação de problemas de redação: palavra desnecessária e distância sujeito-verbo excessiva Fonte: Elaborado pelos autores - (trecho de um dos textos dos alunos) (2021).

A análise de textos de colegas foi duplo-cega, como estratégia para aprofundar o exercício de pensamento e crítica objetiva dos estudantes sobre problemas de redação. Cada estudante recebeu três textos anônimos de colegas para anotar os problemas de estilo dos quatro tipos acima. O professor recebeu, compilou e distribuiu para a turma a coleção de pareceres anônimos. Cada texto teve até quatro pareceres, sem distinguir autoanálise de pareceres de colegas, permitindo a cada estudante conhecer as percepções sobre os problemas de estilo de redação no texto de sua autoria e no de colegas, bem como apreciar a percepção de outros colegas sobre os problemas nos mesmos três textos anônimos que analisou.

Foram conduzidas entrevistas professor-estudante sobre a qualidade da experiência de autoria dos textos originais e reelaborados e de dar e oferecer crítica objetiva. Em particular, o professor queria saber de cada autor(a) se os colegas pareceristas anônimos perceberam os problemas, nos seus quatro tipos, em seus pareceres.

Cada estudante, então, reelaborou o próprio texto, levando em conta os pareceres recebidos, no sentido de resolver os problemas apontados. O professor foi explícito em solicitar uma reelaboração focada na solução dos problemas apontados e não um novo texto com novidades ou omissões essenciais.

Concluído o ciclo de trabalho de seleção de texto, crítica ao próprio texto e aos dos pares e reelaboração corretiva dos problemas encontrados pelos alunos, o professor elaborou estatísticas de extensão e legibilidade dos textos originais e reelaborados. Produziu essas mesmas estatísticas para os textos de referência obtidos na 
literatura. A função de revisão de ortografia e sintaxe do editor de texto Microsoft Word calculou as quantidades de caracteres e palavras e o escore segundo o teste FRE (facilidade de leitura de Flesch).

\section{RESULTADOS}

A seguir, são apresentados os resultados de um estudo de extensão e legibilidade de textos originais e reelaborados pertencentes ao grupo de textos de referência usados nos exercícios preparatórios com os alunos. Depois, apresenta-se o estudo principal, aplicado aos textos originais e reelaborados dos alunos.

\begin{tabular}{|c|c|c|}
\hline \# & Redação original & Redação reelaborada para corrigir estilo \\
\hline Ex 2 & $\begin{array}{l}\text { This component will chiefly involve a description } \\
\text { and quantitative analysis of the study's data col- } \\
\text { lection process. }\end{array}$ & $\begin{array}{l}\text { This component describes and quantitatively } \\
\text { analyzes the data collection process. }\end{array}$ \\
\hline Ex 3 & $\begin{array}{l}\text { Detailed analyses of the evolutionary features } \\
\text { of different types of regulatory elements are an } \\
\text { important area for future research. }\end{array}$ & $\begin{array}{l}\text { Future research should analyze the evolutionary } \\
\text { features of different types of regulatory ele- } \\
\text { ments. }\end{array}$ \\
\hline Ex 4 & $\begin{array}{l}\text { Improvements are expected in the predictive } \\
\text { power of all the scores being computed on mul- } \\
\text { tispecies alignments. }\end{array}$ & $\begin{array}{l}\text { We expect to improve the predictive power of } \\
\text { our multispecies alignment scores. }\end{array}$ \\
\hline Ex 5 & $\begin{array}{l}\text { Some astonishing questions about the nature } \\
\text { of the universe have been raised by scientists } \\
\text { studying the nature of black holes in space. The } \\
\text { collapse of a dead star into a point perhaps no } \\
\text { larger than a marble creates a black hole. }\end{array}$ & $\begin{array}{l}\text { Scientists studying black holes have raised some } \\
\text { astonishing questions about the universe. A black } \\
\text { hole is created by the collapse of a dead star into } \\
\text { a point perhaps no larger than a marble. }\end{array}$ \\
\hline Ex 6 & $\begin{array}{l}\text { The second reaction is really the end result of a } \\
\text { very large number of reactions. It is also worth } \\
\text { noting that these two reactions form a simple } \\
\text { linear chain whereby the product of the first re- } \\
\text { action is the reactant for the second. }\end{array}$ & $\begin{array}{l}\text { The second reaction is the result of numerous } \\
\text { reactions. Moreover, these two reactions form a } \\
\text { simple linear chain whereby the product of the } \\
\text { first reaction is the reactant for the second. }\end{array}$ \\
\hline Ex 7 & $\begin{array}{l}\text { Significant positive correlations were evident } \\
\text { between the substitution rate and a nucleosome } \\
\text { score from resting human T-cells. }\end{array}$ & $\begin{array}{l}\text { In resting human T-cells, the substitution rate cor- } \\
\text { related with a nucleosome score. }\end{array}$ \\
\hline Ex 8 & $\begin{array}{l}\text { We identified genes that are differentially expres- } \\
\text { sed between species. A phylogenetic tree based } \\
\text { on the number of differentially expressed genes } \\
\text { between species recapitulates their known phy- } \\
\text { logeny. }\end{array}$ & $\begin{array}{l}\text { We identified genes that are differentially expres- } \\
\text { sed between species. The number of differenti- } \\
\text { ally expressed genes can be used to build a phylo- } \\
\text { genetic tree that recapitulates the known phylo- } \\
\text { geny. }\end{array}$ \\
\hline $\begin{array}{ll}\text { Ex } 1 \\
\text { again }\end{array}$ & $\begin{array}{l}\text { The model used by the software is a fairly rich } \\
\text { probabilistic model, but it is clearly not realis- } \\
\text { tic in several respects. The assumptions that } \\
\text { all sites evolve at one of two evolutionary rates } \\
\text { (conserved and nonconserved), that these rates } \\
\text { are uniform across the genome, that sites evolve } \\
\text { independently conditional on whether they are } \\
\text { in conserved or nonconserved regions, and that } \\
\text { the phylogenetic models for conserved and non- } \\
\text { conserved regions have the same branch-length } \\
\text { proportions, base compositions, and substitution } \\
\text { patterns, all represent oversimplications of the } \\
\text { complex process of sequence evolution in eu- } \\
\text { karyotic genomes. }\end{array}$ & $\begin{array}{l}\text { Our model admittedly oversimplifies the complex } \\
\text { process of sequence evolution in eukaryotic ge- } \\
\text { nomes by assuming that: (1) all sites evolve at one } \\
\text { of two evolutionary rates (conserved and noncon- } \\
\text { served), (2) these rates are uniform across the } \\
\text { genome, (3) sites evolve independent of whether } \\
\text { they are in conserved or nonconserved regions, } \\
\text { and (4) the phylogenetic models for conserved } \\
\text { and nonconserved regions have the same branch- } \\
\text { length proportions, base compositions, and subs } \\
\text { titution patterns. }\end{array}$ \\
\hline Os $8 \mathrm{Ex}$ & $\begin{array}{l}\text { Todos os trechos originais dos exercícios } \\
\text { concatenados: } \\
\text { A concatenação dos textos originais dos } 8 \\
\text { exercícios acima> }\end{array}$ & $\begin{array}{l}\text { Todos os exercícios resolvidos: } \\
\text { <A concatenação dos textos reelaborados dos } 8 \\
\text { exercícios acima> }\end{array}$ \\
\hline
\end{tabular}

Quadro 3. Textos originais e reelaborados de exercícios resolvidos (Ex) e exemplos de problemas de estilo. Fonte: Adaptado de Sheffield (2011).

\section{Variação de extensão e legibilidade - estudo-referência}

O Quadro 3 reúne os oito exercícios de reelaboração de problemas de estilo propostos por Sheffield (2011), mais uma concatenação desses mesmos oito exercícios. O texto original com problemas, à esquerda, é reelaborado e 


\begin{tabular}{|c|c|c|c|c|c|c|c|c|}
\hline $\begin{array}{l}\text { Texto - } \\
\text { exemplo }\end{array}$ & $\begin{array}{l}\text { Caracte } \\
\text { res (O) }\end{array}$ & $\begin{array}{r}\text { Caracte } \\
\text { res (R) }\end{array}$ & $\begin{array}{l}\text { Palavras } \\
\text { (O) }\end{array}$ & $\begin{array}{l}\text { Palavras } \\
\text { (R) }\end{array}$ & $\begin{array}{l}\text { Senten } \\
\text { ças (O) }\end{array}$ & $\begin{array}{l}\text { Senten } \\
\text { ças (R) }\end{array}$ & $\begin{array}{l}\text { Escore } \\
\text { FRE (O) }\end{array}$ & $\begin{array}{c}\text { Escore FRE } \\
\text { (R) }\end{array}$ \\
\hline$E \times 2$ & 100 & $72_{(-28 \%)}$ & 16 & $10_{(-38 \%)}$ & 1 & 1 & 16,1 & $0,0_{(-16)}$ \\
\hline Ex 3 & 113 & $87_{(-23 \%)}$ & 19 & $13_{(-32 \%)}$ & 1 & 1 & 0,5 & $0,0_{(-1)}$ \\
\hline Ex 4 & 95 & $68(-28 \%)$ & 16 & $12_{(-25 \%)}$ & 1 & 1 & 26,6 & $39,5_{(+13)}$ \\
\hline Ex 5 & 190 & $159_{(-16 \%)}$ & 41 & $33_{(-20 \%)}$ & 2 & 2 & 68,4 & $67,0_{(-1)}$ \\
\hline Ex 6 & 190 & $157_{(-17 \%)}$ & 42 & $31_{(-26 \%)}$ & 2 & 2 & 64,6 & $57,3(-7)$ \\
\hline Ex 7 & 111 & $72_{(-35 \%)}$ & 17 & $12(-29 \%)$ & 1 & 1 & 10,4 & $32,5(+22)$ \\
\hline Ex 8 & 172 & $169_{(-2 \%)}$ & 26 & $28(-8 \%)$ & 2 & 2 & 14,6 & $26,4_{(+12)}$ \\
\hline Ex 1 again & 541 & $424_{(-22 \%)}$ & 91 & $70_{(-23 \%)}$ & 2 & 1 & 3,5 & $0,0_{(-4)}$ \\
\hline Os 8 Ex & 1512 & $1208_{(-20 \%)}$ & 268 & $209_{(-22 \%)}$ & 12 & 11 & 31,6 & $32,5_{(+1)}$ \\
\hline
\end{tabular}

Tabela 2. Indicadores para os textos originais (O) e reelaborados (R) de Sheffield (2011).

Fonte: Elaborado pelos autores (2021).

apresentado à direita no Quadro 3. Esses textos foram estudados para estimar valores plausíveis dos indicadores de extensão e legibilidade, para servir de referência para o estudo principal com os textos dos estudantes-autores.

O motivo de concatenar os oito trechos curtos foi a expectativa de que a aplicação dos princípios de clareza, concisão e coesão aumentaria os escores de legibilidade como tendência geral, mas não necessariamente em todos os trechos, especialmente os curtos. Realmente, foi o que aconteceu, como se verifica na Tabela 2.

Nos oito exercícios, o escore de legibilidade regride em cinco casos e aumenta em três, mas em maior proporção. Na concatenação dos oito trechos, a legibilidade avança levemente. Ou seja, temos variação de -20\% de extensão e ganho de um ponto de legibilidade FRE na concatenação. Esses são indicadores de referência para o estudo principal, apresentado a seguir, embora não possam ser tomados como objetivo ou padrão.

\section{Variação de extensão e legibilidade - estudo principal com textos de alunos}

Na etapa de preparação para a análise, o professor conduziu os alunos na resolução dos oito exercícios de melhoria de legibilidade de Sheffield (2011). Além disso, questionou os alunos sobre princípios elementares de redação científica e surpreendeu-se ao saber que ninguém havia sequer ouvido falar da inconveniência dos parágrafos de sentença única, nem da estrutura de relato científico IMRAD (introduction-method-results-and-discussion). A IMRAD é atribuída a Pasteur, em 1876 (Wu, 2011). É a estrutura clássica do texto científico que se tornou padrão norte-americano em 1979. É explícita nos resumos de muitos periódicos, notadamente os de pesquisa médica, como New England Journal of Medicine, bem como na AtoZ.

Conforme especificado nos Procedimentos, os 25 estudantes entregaram ao professor um parecer sobre texto próprio e três pareceres sobre textos de colegas. Em função de um aluno desistente, três estudantes receberam apenas dois pareceres anônimos de colegas. Isso totaliza 97 pareceres - 25 ao próprio texto e 72 pareceres anônimos dos pares.

O professor entrevistou cada estudante sobre sua experiência de dar e receber crítica, buscando saber, em particular, se as críticas apontavam os quatro tipos de problemas enfocados. Foi possível observar que a maioria dos pareceres tratava de problemas de sintaxe e outros - em adição ou em substituição à análise dos problemas de estilo supostamente enfocados. As possíveis causas dessa troca de objetivos na tarefa de análise são exploradas na próxima seção (Discussão).

Depois, os 25 estudantes entregaram seus textos reelaborados a partir dos problemas apontados nas críticas recebidas. O professor calculou, então, os indicadores da Tabela 3 para cada texto original e reelaborado de estudante de nível de mestrado (M) ou doutorado (D).

Todos os 25 textos diminuíram de extensão após a reelaboração - de $1 \%$ a $22 \%$ caracteres a menos -, bem como em quantidade de palavras. O número de sentenças diminuiu em quatorze textos, ficou estável em oito e aumentou em três.

O escore FRE de legibilidade aumentou em treze casos, o que era esperado, mas ficou estável em dois e diminuiu em dez. Dentre os 25 textos originais, seis estão na faixa de leitura "Difícil" conforme a Tabela 1 e pressupõem que o leitor tem nível universitário, enquanto 19 são de leitura "Muito difícil", que pressupõe a leitura apenas por universitários graduados. Dois desses, na versão reelaborada, passaram de "Muito difícil" a "Difícil".

O maior avanço em legibilidade entre o texto original e o reelaborado foi de oito pontos (em três casos) e o maior recuo, de sete pontos. Os textos de mestrandos melhoraram a legibilidade em seis, mantiveram a legibilidade em dois e perderam legibilidade em cinco casos, enquanto doutorandos melhoraram a legibilidade em sete casos e perderam legibilidade em cinco. A Figura 2 ilustra essa distribuição dos escores de legibilidade. 


\begin{tabular}{|c|c|c|c|c|c|c|c|c|}
\hline $\begin{array}{l}\text { Texto - } \\
\text { nível }\end{array}$ & $\begin{array}{l}\text { Caracte } \\
\text { res (O) }\end{array}$ & $\begin{array}{r}\text { Caracte } \\
\text { res (R) }\end{array}$ & $\begin{array}{l}\text { Palavras } \\
\text { (O) }\end{array}$ & $\begin{array}{l}\text { Palavras } \\
\text { (R) }\end{array}$ & $\begin{array}{l}\text { Senten } \\
\text { ças (0) }\end{array}$ & $\begin{array}{l}\text { Senten } \\
\text { ças (R) }\end{array}$ & $\begin{array}{l}\text { Escore } \\
\text { FRE (O) }\end{array}$ & $\begin{array}{c}\text { Escore FRE } \\
\text { (R) }\end{array}$ \\
\hline $\mathrm{T} 1-\mathrm{M}$ & 1975 & $1817_{(-8 \%)}$ & 334 & $306_{(-8 \%)}$ & 10 & 9 & 14 & $13_{(-1)}$ \\
\hline $\mathrm{T} 2-\mathrm{M}$ & 1943 & $1739_{(-10 \%)}$ & 323 & $290(-10 \%)$ & 10 & 10 & 12 & $16_{(+4)}$ \\
\hline T3 - M & 2682 & $2367_{(-12 \%)}$ & 460 & $402(-13 \%)$ & 17 & 15 & 24 & $22(-2)$ \\
\hline $\mathrm{T} 4-\mathrm{M}$ & 4654 & $4509_{(-3 \%)}$ & 806 & $780_{(-3 \%)}$ & 26 & 21 & 21 & $15(-6)$ \\
\hline T5 - D & 3297 & $3070_{(-7 \%)}$ & 545 & $497(-9 \%)$ & 24 & 17 & 14 & $22_{(+8)}$ \\
\hline T6-M & 3533 & $2941_{(-17 \%)}$ & 632 & $526(-17 \%)$ & 20 & 20 & 27 & $32_{(+5)}$ \\
\hline T7 - D & 2953 & $2860_{(-3 \%)}$ & 546 & $517_{(-5 \%)}$ & 17 & 18 & 33 & $32(-1)$ \\
\hline T8 - D & 3385 & $3274(-3 \%)$ & 599 & $579_{(-3 \%)}$ & 17 & 17 & 21 & $22_{(+1)}$ \\
\hline T9 - D & 3636 & $3511_{(-3 \%)}$ & 621 & $592(-5 \%)$ & 20 & 18 & 19 & $14_{(-5)}$ \\
\hline T10 - M & 3870 & $3054_{(-21 \%)}$ & 685 & $539_{(-21 \%)}$ & 26 & 24 & 30 & $34_{(+4)}$ \\
\hline T11 - D & 2991 & $2966_{(-1 \%)}$ & 525 & $520_{(-1 \%)}$ & 19 & 20 & 27 & $29_{(+2)}$ \\
\hline T12 - M & 2820 & $2674_{(-5 \%)}$ & 511 & $4799_{(-6 \%)}$ & 16 & 13 & 29 & $22(-7)$ \\
\hline T13 - M & 3825 & $3555(-7 \%)$ & 691 & $631_{(-9 \%)}$ & 23 & 23 & 31 & $30_{(-1)}$ \\
\hline T14 - D & 3409 & $2846(-17 \%)$ & 632 & $538(-15 \%)$ & 36 & 25 & 48 & $47_{(-1)}$ \\
\hline T15 - D & 2567 & $2168_{(-16 \%)}$ & 417 & $357(-14 \%)$ & 14 & 14 & 10 & $17_{(+7)}$ \\
\hline T16-M & 1885 & $1688_{(-10 \%)}$ & 327 & $295_{(-10 \%)}$ & 12 & 12 & 26 & $30_{(+4)}$ \\
\hline T17 - M & 4870 & $4234_{(-13 \%)}$ & 825 & $715_{(-13 \%)}$ & 28 & 26 & 19 & $20_{(+1)}$ \\
\hline T18 - D & 3402 & $2886_{(-15 \%)}$ & 589 & $501_{(-15 \%)}$ & 17 & 17 & 18 & $23_{(+5)}$ \\
\hline T19- M & 1730 & $1647_{(-2 \%)}$ & 293 & $275(-6 \%)$ & 9 & 9 & 15 & 15 (0) \\
\hline T20 - D & 2812 & $2240_{(-20 \%)}$ & 506 & 416 (-18\%) & 23 & 13 & 38 & $34(-4)$ \\
\hline T21 - D & 3522 & $2759_{(-22 \%)}$ & 575 & $458(-20 \%)$ & 18 & 17 & 9 & $17_{(+8)}$ \\
\hline T22 - M & 3871 & $3078_{(-20 \%)}$ & 704 & $572(-19 \%)$ & 24 & 22 & 32 & $40_{(+8)}$ \\
\hline T23 - D & 3110 & $3090_{(-1 \%)}$ & 578 & $571_{(-1 \%)}$ & 15 & 16 & 27 & $29_{(+2)}$ \\
\hline T24 - D & 3723 & $3351_{(-10 \%)}$ & 650 & $578_{(-11 \%)}$ & 20 & 18 & 22 & $20_{(-2)}$ \\
\hline T25 - M & 3092 & $2903(-6 \%)$ & 552 & $517(-6 \%)$ & 15 & 14 & 21 & $21_{(0)}$ \\
\hline
\end{tabular}

Tabela 3. Indicadores de extensão e legibilidade dos textos originais $(\mathrm{O})$ e reelaborados (R).

Fonte: Elaborado pelos autores (2021).

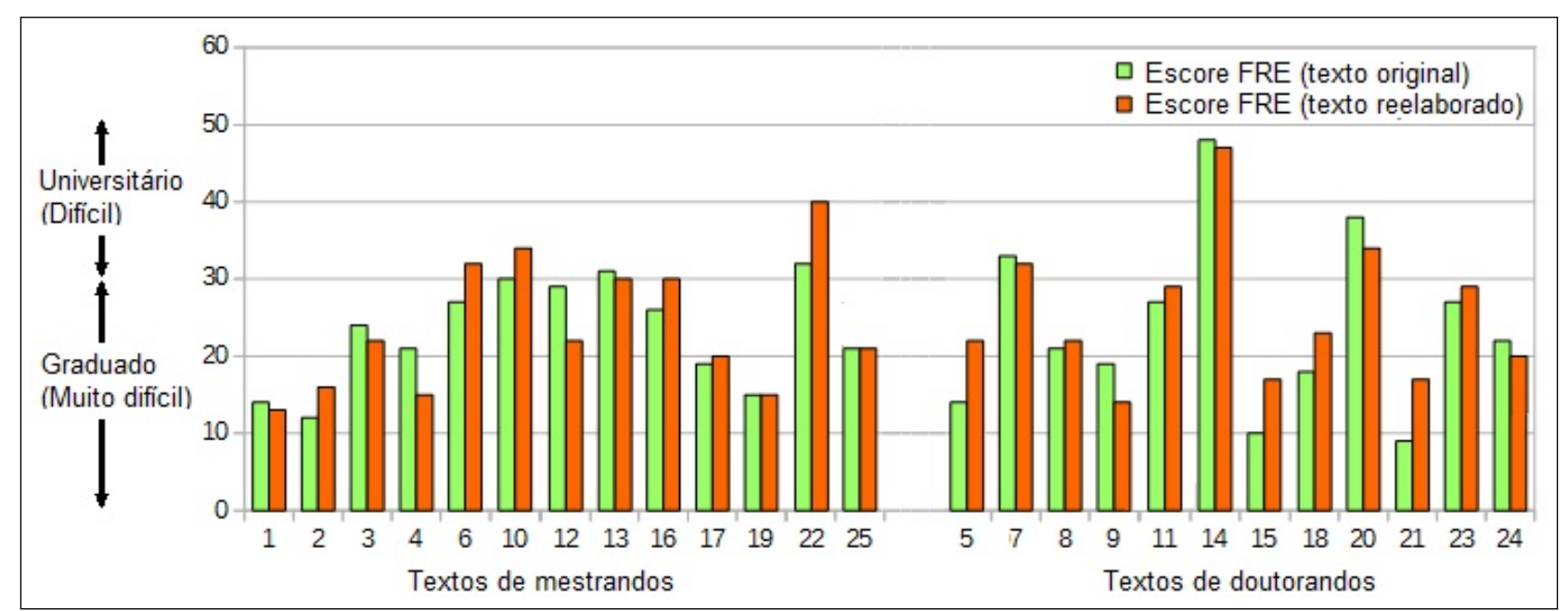

Figura 2. Distribuição dos escores de legibilidade em textos originais e reelaborados Fonte: Elaborado pelos autores (2021).

O saldo total dos 25 estudantes foi de 29 pontos de melhora de legibilidade entre o texto original e o reelaborado, embora isso revele apenas uma tendência e não tenha sentido estatístico (essa soma não tem significado, de forma semelhante a uma soma ou média de fatores de impacto). A intensidade do avanço foi maior entre doutorandos, mas as quantidades de avanços e recuos de legibilidade foram semelhantes nos dois níveis de formação.

O avanço médio dos mestrandos foi de 0,7 ponto, com melhora de legibilidade em seis casos, manutenção em dois e perda de legibilidade em cinco. Os textos de doutorandos avançaram 1,7 ponto em média, com melhora de legibilidade em sete casos e perda em cinco. O significado desses resultados é discutido a seguir.

\section{DISCUSSÃO}

A aplicação de quatro princípios de estilo de Sheffield (2011) aos textos dos alunos é discutida aqui quanto ao efeito sobre extensão e o escore de legibilidade. Desses aspectos, só a extensão melhorou em todos os casos. 
Diminuiu tanto na reelaboração dos 25 textos dos alunos quanto no estudo-referência a partir de exemplos e exercícios de Sheffield (2011).

Se o conteúdo permanece o mesmo e a extensão diminui, conclui-se que melhorou a concisão, muito enfatizada por Zinsser (2001) e por Strunk e White (1999). Já a relação da extensão do texto com a clareza e a coesão não é óbvia. Talvez seja muito dependente de cada caso e desconhecemos estudos que as testem.

Quanto ao escore de legibilidade, não foi confirmada a expectativa de que aumentaria com a aplicação dos princípios de estilo. No estudo-referência com textos de Sheffield (2011), a concatenação, com extensão média (1512 caracteres, na Tabela 2), teve um leve avanço no escore (um ponto), enquanto os oito exercícios (textos de 95 a 541 caracteres) tiveram avanços e recuos (entre -16 e +22 pontos). Nos 25 textos de alunos relatados na Tabela 3, houve 10 recuos (o maior, -7 pontos), duas estabilidades e 13 avanços (três deles de oito pontos).

É certo que, entre os 25 textos, houve um avanço mediano de um ponto e houve mais avanços que recuos, mas a relação entre estilo (segundo os quatro problemas tratados) e legibilidade (segundo o escore FRE) não fica bem caracterizada. Isso é compatível com o estudo-referência, que teve -1 como variação mediana do escore de legibilidade dos oito exemplos curtos, mas apresentou um crescimento modesto $(+1$ e +3$)$ nos dois trechos mais extensos.

Esses resultados ambíguos refletem a falta de consenso sobre a relação entre escore de legibilidade e qualidade estilística do texto. Fages (2020) associa boa legibilidade a mais downloads, citações e prêmios, mas Mubin, Tejlavwala, Arsalan, Ahmad, e Simoff (2018) compararam a legibilidade de artigos premiados e não-premiados no evento ACM Conference on Human Factors in Computing Systems e encontraram que os premiados têm menos legibilidade que os não-premiados. O próprio Kincaid reconheceu as debilidades das fórmulas de legibilidade e defendeu que servem como ferramenta de avaliação para revisão de texto, mas não são ferramentas de redação, nem devem ser usadas antes de haver um rascunho completo (McClure, 1987). Dessa forma, podem-se usar as métricas para estimar a legibilidade de versões distintas de um mesmo texto, mas os escores de legibilidade para textos diferentes não podem ser comparados de forma categórica. Um escore menor não implica, necessariamente, em menor legibilidade.

Além da apreciação objetiva dos experimentos, cabe apresentar a percepção do professor da disciplina Redação e Avaliação Científica (e primeiro autor deste artigo). Das intervenções para melhorar o estilo, "omitir palavras desnecessárias" foi a mais bem compreendida e aplicada pelos alunos, com larga vantagem. Tem relação direta com a extensão do texto e é pouco sujeita a nuances, ao contrário dos outros três princípios - "expressar ações em verbos" (será que "analisar" é sempre melhor que "análise"?), "colocar verbos próximos a seus sujeitos" (será que um aposto intermediário é sempre prejudicial?) e "apresentar informação familiar primeiro" (não parece haver dúvida de que isso melhora a coesão, mas detectar o problema da contextualização tardia costuma ser um desafio).

Chamou a atenção do professor o fato de que muitos pareceres anônimos deixaram despercebidos problemas de estilo e enfocaram mais os problemas sintáticos. Isso parece compatível com a atenção que a escola fundamental e média dá aos problemas de sintaxe, como concordância de gênero e número, regência verbal e nominal, pontuação, entre outros, sem trabalhar questões de estilo de texto.

É possível que, dada a falta de experiência com problemas de estilo, muitos alunos tenham dedicado atenção aos problemas sintáticos, que conhecem melhor, o que também contribui para melhorar a redação. Ainda assim, resta o desafio de conduzir melhor os alunos no enfrentamento dos problemas de estilo. A omissão de palavras desnecessárias parece bem apreendida, mas é possível que os alunos requeiram uma preparação bem mais aprofundada para lidar com a nominalização excessiva, a distância sujeito-verbo excessiva e, em especial, o fluxo ruim causado pela contextualização tardia.

Além dos quatro problemas enfocados, futuramente pode-se atacar o uso excessivo da voz passiva (que o editor de texto MS-Word detecta, pelo menos em inglês) e a inversão sintática tão comum na cultura redacional brasileira (da qual esta sentença é exemplo, ao iniciar pelo predicado). Uma questão pontual, mas não menos importante, é o uso de acrônimos não usuais, como "CI", que alienam o leitor de outra área do conhecimento e até aumentam o escore de legibilidade - no caso, ao substituir três palavras, "Ciência da Informação", por uma de duas letras, "CI", ao custo da perda do significado. Nesse sentido, Barnett e Doubleday (2020) alertam para o uso crescente de acrônimos não consolidados. Meadows (1999) reconhece a tendência de serem mais frequentes as palavras menores, conforme a Lei de Zipf. Exemplifica com o caso do termo "ácido desoxirribonucleico", cujo uso intenso resultou na popularização (consolidação) do acrônimo "DNA", que se tornou de uso corrente, dicionarizado. Não é o caso de "CI".

Há que reconhecer, finalmente, uma limitação importante da nossa abordagem: falamos de qualidade de texto científico, mas não de qualidade científica, mérito científico. De qualquer forma, o domínio do estilo de texto científico é relevante, pois o mau estilo - sem clareza, concisão e coesão - pode impedir a publicação de ciência meritória. 


\section{CONSIDERAÇÕES FINAIS}

Este artigo apresentou uma experiência de aprendizagem de princípios de estilo de texto científico (Sheffield, 2011) para resolver quatro problemas: palavra desnecessária, distância sujeito-verbo excessiva, nominalização excessiva e contextualização tardia. Calculamos índices de legibilidade (Kincaid et al., 1975) antes e depois da reelaboração dos textos originais de 25 estudantes. Exemplos de problemas de estilo (Sheffield, 2011) foram também medidos quanto à sua legibilidade, para servir como termo de referência.

Todos os textos dos estudantes diminuíram a quantidade de caracteres após a correção dos problemas de estilo, da mesma forma que os textos de referência. Os indicadores de legibilidade foram variados: 13 textos de estudantes aumentaram a legibilidade FRE (Flesch Reading Ease) após a correção dos problemas, mas dez diminuíram e dois permaneceram estáveis. Apenas dois textos tiveram sua legibilidade aumentada a ponto de transpor a barreira de leitura "muito difícil" para "difícil", o que parece um avanço significativo, dado que os maiores índices de legibilidade requereriam sentenças tão simples, como "Ivo viu a uva", que são impraticáveis num texto acadêmico. Em conclusão, a alta qualidade do estilo científico parece ter relação duvidosa com os índices de legibilidade, mas tem clara relação inversa com a extensão do texto.

Este estudo de métricas de legibilidade, na interface da Ciência da Informação com a linguística, diferencia-se dos estudos bibliométricos e cientométricos mais usuais, frequentemente baseados nas citações e nas quantidades de publicações. Há poucos estudos na Ciência da Informação envolvendo legibilidade ou estilo de texto, embora Meadows (1999) dedique uma seção de seu livro à legibilidade (pp. 121-124), com breve menção às métricas. Os estudos recentes de Mubin et al. (2018) e Fages (2020), já citados, são raros exemplos de pesquisas com métricas de legibilidade na Ciência da Informação.

Adicionalmente, Morato, Sánchez-Cuadrado, e Gimmelli (2018) avaliaram a compreensibilidade de painéis explicativos em museus, usando métricas para estimar a dificuldade do texto. Também Albán Defilippi, Miller, e Ramirez-Avila (2020) mediram os progressos de aprendizes de línguas estrangeiras, outro dos poucos estudos métricos sobre o conteúdo dos documentos.

Há pesquisas sobre estilo de texto no Brasil, embora sem envolver métricas de legibilidade. Sordi (2009) usou análise de redes sociais para estudar a coesão entre seções de um documento extenso. Ferreira (2011) identificou 101 atributos de qualidade da informação a partir da literatura científica em inglês em Ciência da Informação. Cuenca, de Paula, e Junior (2017) compararam a produtividade de autores antes e após passarem por cursos de aprimoramento da habilidade na escrita científica, encontrando avanços.

Métricas de estilo e legibilidade são uma possível adição aos estudos métricos da comunicação científica. Em particular, a relação entre o status científico de artigos e revistas e seus indicadores de legibilidade parece merecer atenção em pesquisas futuras. A investigação da traduzibilidade de textos que seguem ou não princípios de legibilidade é uma decorrência natural desta pesquisa, para testar a hipótese de que aplicar esses princípios é "escrever em inglês em português". 


\section{REFERÊNCIAS}

Albán Defilippi, M. T., Miller, K. L., \& Ramirez-Avila, M. R. (2020). Collaboration to improve descriptive writing facilitated by padlet: an english as a foreign language (efl) action research study. AtoZ, 9(1). doi: 10.5380/atoz.v9i1.73517

Barnett, A., \& Doubleday, Z. (2020). Science is becoming less readable as the number of new acronyms boom. SocArXiv preprint, 1. Recuperado de https://osf.io/y7zqb/

Cuenca, A. M. B., de Paula, D., \& Junior, I. F. (2017). Desenvolvimento da habilidade na escrita e a produção científica: cursos são necessários? Revista Eletrônica de Comunicação, Informação e Inovação em Saúde, 11(3). doi: 10.29397/reciis.v11i3.1166

Fages, D. M. (2020). Write better, publish better. Scientometrics, 122(3), 1671-1681. doi: 10.1007/s11192-019-03332-4

Ferreira, O. C. A. (2011). Atributos de qualidade da informação. Revista Ibero-Americana de Ciência da Informação, 8(2), 276-277.

Flesch, R. (1948). A new readability yardstick. Journal of applied psychology, 32(3), 221. doi: 10.1037/h0057532

Guimarães, J. A. (2004). A pesquisa médica e biomédica no brasil: comparações com o desempenho científico brasileiro e mundial. Ciência ES Saúde Coletiva, 9, 303-327. doi: 10.1590/S1413-81232004000200009

Kern, V. M., Pellegrini, E., Mendonça, T. C., Fagundes, L. L., Priscila Bastoand Günther, Mello, J., Sembay, M. J., ... Afonso, R. D. (2019). Clareza, concisão e coesão para "escrever em ingl`s em portugu^s": princípios e métricas de legibilidade aplicados ao texto de pósgraduandos. Wikipedia, The Free Encyclopedia. Recuperado de https://osf.io/5vqce/

Kincaid, J. P., Fishburne Jr., R. P., Rogers, R. L., \& Chissom, B. S. (1975). Derivation of new readability formulas (automated readability index, fog count and flesch reading ease formula) for navy enlisted personnel (Relatório Técnico). Millington, TN: Naval Technical Training Command Millington TN Research Branch. Recuperado de http://www.dtic.mil/get-tr-doc/pdf?AD=ADA006655

McClure, G. M. (1987). Readability formulas: Useful or useless? IEEE transactions on professional communication, 33(1), 12-15. doi: 10.1109/TPC.1987.6449109

Meadows, A. J. (1999). A comunicação científica. BrasíliaDF: Briquet de Lemos.

Morato, J., Sánchez-Cuadrado, S., \& Gimmelli, P. (2018). Estimación de la comprensibilidad en paneles de museos. El profesional de la información, 27(3), 570-581. doi: 10.3145/epi.2018.may.10

Mubin, O., Tejlavwala, D., Arsalan, M., Ahmad, M., \& Simoff, S. (2018). An assessment into the characteristics of award winning papers at chi. Scientometrics, 116(2), 1181-1201. doi: 10.1007/s11192-018-2778-7

Organização das Nações Unidas para a Educação, a Ciência e a Cultura. (2011, 8 de Setembro). Relatório de ciência da unesco: Rumo a 2030 - visão geral e cenário brasileiro (Relatório Técnico). Paris: Unesco. Recuperado de http:/ unesdoc.unesco.org/images/0023/002354/235407por.pdf

Rabinowitz, H., \& Vogel, S. (2009). The manual of scientific style: a guide for authors, editors, and researchers. Burlington-MA, San Diego-CA, London: Academic Press.

Sheehan, K. M. (2013). Measuring cohesion: An approach that accounts for differences in the degree of integration challenge presented by different types of sentences. Educational Measurement: Issues and Practice, 32(4), 28-37. doi: 10.1111/emip. 12017

Sheffield, N. (2011, 8 de Setembro). Scientific writing: clarity, conciseness, and cohesion (Relatório Técnico). Millington, TN: Institute for Genome Sciences and Policy, Duke University, in collaboration with Duke Writing Studio. Recuperado de https://cgi.duke.edu/web/sciwriting/resources/ 201108 _DukeScientificWritingWorkshop.pdf

Sordi, J. O. d. (2009). Análise da coesão entre seções de textos de documentos extensos apartir da aplicação conjunta das técnicas de análise de redes sociais e referências internas. Perspectivas em Ciência da Informação, 14(1), 152-169. doi: 10.1590/S1413-99362009000100011

Strunk, W., \& White, E. B. (1999). The elements of style (4a. ed.). New York: Longman.

Volpato, G. L. (2007). Bases teóricas para redação cientifica... por que seu artigo foi negado? São Paulo: Cultura Academica.

Volpato, G. L. (2011). Método lógico para redação científica. Botucatu: Best Writing.

Wikipedia contributors. (2018, 21 de Janeiro). Readability. Wikipedia, The Free Encyclopedia. Recuperado de https://en.wikipedia.org/w/index.php?title= Readability\&oldid $=821584226$

Wikipedia contributors. (2021, 31 de Janeiro). Flesch-kincaid readability tests. Wikipedia, The Free Encyclopedia. Recuperado de https://en.wikipedia.org/w/ index.php?title=Flesch\%E2\%80\%93Kincaid_readability tests\&oldid $=1004021607$

$\mathrm{Wu}$, J. (2011). Improving the writing of research papers: Imrad and beyond (v. 26) (n. 10). Springer. doi: 10.1007/s10980-011-9674-3

Zinsser, W. (2001). On writing well: The classic guide to writing nonfiction (25th anniv. ed.). New York: Harper Resource.

Como citar este artigo (APA):

Kern, V. M., Pellegrini, E., Mendonça, T. C., Fagundes, P. B., Günther, L. L., Mello, J., Sembay, M. J., ... \& Afonso, R. D. (2021). Clareza, concisão e coesão: princípios e métricas de legibilidade aplicados ao texto de pós-graduandos em Ciência da Informação ${ }^{4}$. AtoZ: novas práticas em informação e conhecimento, 10(2), 27 - 37. Recuperado de: http://dx.doi.org/10.5380/ atoz.v10i2.77975

\footnotetext{
${ }^{4}$ Publicado anteriormente como preprint por Kern et al. (2019) Disponível em https://osf.io/5vqce/
} 